\title{
Smoking as an independent predictor of reoperation after lumbar laminectomy: a study of 500 cases
}

\author{
*Mohamad Bydon, MD,,2 Mohamed Macki, BS,, Rafael De la Garza-Ramos, MD,,,2 \\ Daniel M. Sciubba, MD, ${ }^{1}$ Jean-Paul Wolinsky, MD, ${ }^{1}$ Ziya L. Gokaslan, MD, ${ }^{1,2}$ \\ Timothy F. Witham, MD, ${ }^{1}$ and Ali Bydon, MD ${ }^{1,2}$ \\ 1'Department of Neurosurgery, Johns Hopkins University School of Medicine; and 2Johns Hopkins Spinal Biomechanics and \\ Surgical Outcomes Laboratory, Baltimore, Maryland
}

OBJECT This study aimed to identify the factors predicting an increased risk for reoperation in patients who had undergone a lumbar laminectomy.

METHODS The authors retrospectively reviewed the electronic medical records of all patients who had undergone firsttime, bilateral laminectomy at 1, 2, or 3 levels for lumbar spondylosis at the authors' institution. Patients who underwent fusion, laminotomy, discectomy, or complete facetectomy were excluded. The patients' preoperative symptoms and comorbidities were also obtained from their medical records.

RESULTS Over an average follow-up period of 46.8 months, of 500 patients who had undergone laminectomy at 1, 2, or 3 levels, 81 patients (16.2\%) developed subsequent spinal disorders that required a reoperation. A multiple logistic regression analysis identified smoking as an independent predictor of reoperation (OR 2.15, $p=0.01)$. Smoking was also an independent predictor of reoperation after a single-level laminectomy (OR 11.3, $p=0.02)$ and after a multilevel (that is, involving 2 or 3 levels) laminectomy (OR 1.98, $p=0.05$ ). For 72 patients undergoing reoperation only for spinal degeneration, smoking remained an independent, statistically significant predictor of reoperation $(\mathrm{OR} 2.06, p=0.04)$. Nine patients underwent reoperation for nondegenerative conditions (hematoma, wound infection, or wound dehiscence), and in these patients, chronic obstructive pulmonary disease was the only statistically significant predictor of reoperation (OR 8.92, $p=0.03$ ).

CONCLUSIONS Smoking was the strongest predictor of reoperation in patients who had undergone single-level laminectomy, multilevel laminectomy, or reoperation for progression of spinal degeneration. These findings suggest that smokers have worse outcomes of lumbar decompression than nonsmokers.

http://thejns.org/doi/abs/10.3171/2014.10.SPINE14186

KEY WORDS decompression; laminectomy; lumbar; predictor; reoperation; smoking; spinal disorders

$\mathrm{R}$ EOPERATION rates after posterior decompression of the lumbar spine approach $15 \%$ over 5 years after the index surgery. ${ }^{13}$ Given this high incidence of repeat surgery, several studies have sought to characterize the prognostic factors that predict the risk for reoperation. In a prospective study of 203 patients undergoing decompression and posterolateral fusion, Cobo Soriano et al. found that good emotional health predicts improved clini- cal outcomes, whereas smoking and severe lumbar pain are predictors of poor outcomes. ${ }^{4}$ Similar studies of outcomes of laminectomy without fusion have shown that a higher number of preoperative comorbidities predict poor outcomes. ${ }^{5,11}$ In this study, we aimed to determine the specific preoperative prognostic factors associated with risk for reoperation in patients who have undergone a lumbar laminectomy.

ABBREVIATION COPD = chronic obstructive pulmonary disease.

SUBMITTED February 16, 2014. ACCEPTED October 30, 2014.

INCLUDE WHEN CITING Published online January 2, 2015; DOI: 10.3171/2014.10.SPINE14186.

DISCLOSURE Dr. Ali Bydon is the recipient of a research grant from DePuy Spine and serves on the clinical advisory board of Medlmmune, LLC. Dr. Gokaslan is the recipient of research grants from DePuy Spine, AOSpine North America, Medtronic, NREF, Integra Life Sciences, and K2M; receives fellowship support from AOSpine North America; and holds stock in Spinal Kinetics and US Spine. Dr. Witham is the recipient of a research grant from Eli Lilly \& Co and The Gordon \& Marilyn Macklin Foundation. Dr. Sciubba is the recipient of a research grant from DePuy Spine and has consulting relationships with Medtronic, NuVasive, Globus, and DePuy Spine.

* Dr. Mohamad Bydon and Mr. Macki contributed equally to this work. 


\section{Methods}

We retrospectively reviewed the medical records of all patients undergoing first-time, bilateral lumbar laminectomy for degenerative spinal disease from 1990 to 2012 at our institution. Patients undergoing discectomy, hemilaminectomy, laminotomy, and laminoplasty were excluded, as were patients with complete facetectomy, fusion, or both (instrumented or in situ). To maintain the consistency, adequacy, and accuracy of data collection, all charts were reviewed by a single researcher and confirmed by a senior neurosurgeon.

Our study population was limited to patients undergoing a 1-, 2-, or 3-level lumbar laminectomy. A total of 500 patients met our selection criteria. Comorbidities, including coronary artery disease, diabetes mellitus, osteoporosis, obesity, ever smoking (that is, past or present smoking), chronic obstructive pulmonary disease (COPD), hypertension, and depression were obtained from clinical notes. Medical history, including smoking history, was documented on the first visit to the clinic; thus, these potential predictors were passively ascertained. Although we did not establish a minimum smoking threshold, a positive smoking history (past or present) was reported in the medical records when the duration or frequency of smoking was clinically relevant.

For those of the 500 patients who later required a reoperation, we also evaluated their clinical characteristics. Indications for reoperation included wound dehiscence, infection, hematoma, and progression of spinal degeneration. The latter was defined either as progression of the initial spinal disorder or as a spinal disorder at the adjacent segment. The primary end point of the study was to identify predictors of reoperation in patients who had previously undergone a lumbar laminectomy. However, as with all cohort studies, a follow-up bias may lead to underreporting of the true outcome rate (that is, the rate of reoperation). To minimize these errors, patients who did not return for postoperative visits at the clinic were contacted.

The predictors of reoperations were analyzed separately for all-type reoperations, reoperations for progression of degenerative disease, reoperations for nondegenerative conditions, reoperations in patients who had undergone a single-level laminectomy, and reoperations in patients who had undergone a multilevel laminectomy. In considering the number of laminectomy levels (that is, singlelevel versus multilevel), we a priori set the number of spinal levels as an effect measure modifier, rather than as a confounder (that is, as a covariate in regression analysis). By stratifying the outcome, that is, reoperation, according to single-level versus multilevel laminectomy groups, we followed the assumption that the number of spinal levels decompressed modified the association between reoperation and its independent predictors.

Patient demographics are described with summary statistics. Patients not undergoing reoperations (that is, the nonreoperation group) were compared with patients undergoing reoperation (the reoperation group) (Table 1). Binary outcomes were compared with a chi-square test. Because of the unequal sample sizes in the nonreoperation and reoperation groups, continuous variables were first compared with a variance ratio test, followed by the appropriate t-test. A binary logistic regression model was fitted to the data to estimate the effect of preoperative predictors on reoperation. The results of simple and multiple logistic regression analyses are reported with odds ratios. When the effect of the outcome was small, an exact logistic regression analysis was used. In the simple logistic regressions, we controlled for the following predictors: age, patient comorbidities (as listed above), and postoperative clinical symptoms (back pain, radiculopathy, lowerextremity sensory deficits, lower-extremity weakness, lower-extremity neurogenic claudication, and bowel/bladder dysfunction) after the index operation. Only predictors that were statistically significant in the simple logistic regression were included in the multiple logistic regression. Statistical significance was set at $\mathrm{p} \leq 0.05$.

\section{Results}

We identified 500 patients who underwent first-time lumbar laminectomy at 1,2, or 3 levels for treatment of degenerative spinal disease at our institution (Table 1). The patients were followed up on average for 46.8 months (the follow-up length ranged from at discharge from the hospital after the index operation to 7.8 years). Among the 500 patients, $7.6 \%$ underwent a 1-level laminectomy, $43.6 \%$ underwent a 2-level laminectomy, and $48.8 \%$ underwent a 3-level laminectomy (Fig. 1). Within this study cohort, 81 patients $(16.2 \%)$ underwent a reoperation.

The demographics and other characteristics of the 81 patients who underwent a reoperation were compared with those of the 419 patients in the nonreoperation group $(83.8 \%)$ (Table 1). The 2 groups did not statistically significantly differ in the sex ratio. The 2 groups also did not differ in the prevalence of many comorbidities, including coronary artery disease, diabetes mellitus, osteoporosis, COPD, hypertension, and depression. However, patients in the reoperation group exhibited a significantly higher prevalence of obesity $(\mathrm{p}=0.02)$ and of past or present smoking $(\mathrm{p}=0.002)$.

Among the 81 reoperations, the most common indication was progression of spinal degeneration $(n=72$, $88.9 \%$ ) (Table 2). Of the 500 patients in the study cohort, $2(0.4 \%)$ developed wound dehiscence, $1(0.2 \%)$ of which required surgical closure. Twelve patients $(2.4 \%)$ developed an infection at the surgical site, 6 of which $(1.2 \%)$ required surgical debridement. Lastly, 3 patients $(0.6 \%)$ developed a hematoma, all of which required a surgical evacuation.

A simple logistic regression indicated that both obesity (OR 2.95, $\mathrm{p}=0.02$ ) and smoking (OR 2.37, $\mathrm{p}=0.002)$ were statistically significant predictors of reoperation and that older age had a protective effect on reoperation (OR 0.96, $\mathrm{p}=0.008$ ). Using multiple logistic regression, we controlled for age, obesity, and smoking and for postoperative weakness in the lower extremities, neurogenic claudication, sensory deficits, and radiculopathy. This analysis indicated smoking as an independent predictor of reoperation (OR 2.15, $\mathrm{p}=0.01$ ), along with postoperative weakness in the lower extremities (OR 5.27, p < 0.001 ), neurogenic claudication (OR 6.04, $\mathrm{p}<0.001$ ), and radiculopathy (OR 11.35, $\mathrm{p}<0.001)$ (Fig. 2). 
TABLE 1. Potential prognostic factors for reoperation in 500 patients undergoing lumbar laminectomy for degenerative spine diseases*

\begin{tabular}{|c|c|c|c|}
\hline \multirow[b]{2}{*}{ Variable/Factor } & \multicolumn{2}{|c|}{ Patient Group } & \multirow[b]{2}{*}{ p Value } \\
\hline & Nonreoperation & Reoperation & \\
\hline All patients & $419(83.8)$ & $81(16.2)$ & \\
\hline Male sex & $238(56.8)$ & $46(56.8)$ & 0.99 \\
\hline \multicolumn{4}{|l|}{ Comorbidities } \\
\hline Coronary artery disease & $52(12.4)$ & $8(9.9)$ & 0.52 \\
\hline Diabetes mellitus & $64(15.3)$ & $7(8.6)$ & 0.11 \\
\hline Osteoporosis & $11(2.6)$ & $5(6.2)$ & 0.09 \\
\hline Obesity & $13(3.1)$ & $7(8.6)$ & 0.02 \\
\hline Past/present smoking & $60(14.3)$ & $23(28.4)$ & 0.002 \\
\hline COPD & $14(3.3)$ & $5(6.2)$ & 0.22 \\
\hline Hypertension & $166(39.6)$ & $34(42.0)$ & 0.69 \\
\hline Depression & $27(6.4)$ & $9(11.1)$ & 0.13 \\
\hline \multicolumn{4}{|l|}{ Intraop parameters of index surgery } \\
\hline Median no. of spinal levels decompressed & 2 & 2 & \\
\hline Median blood loss in ml (IQR) & $300(225-375)$ & $150(50-250)$ & \\
\hline Durotomy & $46(11.0)$ & $2(2.5)$ & 0.01 \\
\hline \multicolumn{4}{|l|}{ Postop course } \\
\hline Mean LOS in days (SD) & $4.2(4.0)$ & $3.7(2.2)$ & 0.12 \\
\hline Postop CSF leakage & $6(1.4)$ & $2(2.5)$ & 0.49 \\
\hline Wound dehiscence & $1(0.2)$ & $1(1.2)$ & 0.19 \\
\hline Wound infection & $6(1.4)$ & $6(7.4)$ & 0.001 \\
\hline Hematoma & $0(0.0)$ & $3(3.7)$ & $<0.001$ \\
\hline Deep vein thrombosis & $1(0.2)$ & $0(0.0)$ & 0.66 \\
\hline Pulmonary embolus & $1(0.2)$ & $0(0.0)$ & 0.66 \\
\hline
\end{tabular}

$\mathrm{IQR}=$ interquartile range; $\mathrm{LOS}=$ length of stay; $\mathrm{Sx}=$ surgery.

* The values shown in this table are number of patients (\%), unless indicated otherwise.

Over a mean period of 41.4 months, 72 patients underwent reoperation for spinal degeneration. Among these patients, the most common indication for reoperation was disc degeneration and/or spinal stenosis at the index or distal level (73.6\%), followed by new or worsening spondylolisthesis (19.4\%), spinal cysts (4.2\%), and scoliosis (1.4\%). In these 72 cases, smoking remained an independent, statistically significant predictor of reoperation (OR $2.06, p=0.04)$ in a multiple logistic regression model con-

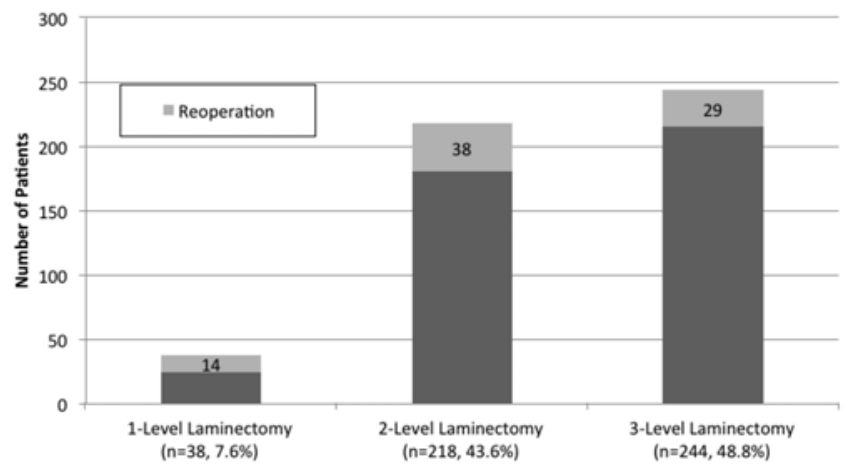

FIG. 1. Number of patients undergoing single-level, 2-level, and 3-level laminectomy. The number of reoperations are indicated in light gray and the number of index operations in dark gray.
TABLE 2. Characteristics and indicators of the reoperations after initial lumbar laminectomy

\begin{tabular}{ll}
\hline \multicolumn{1}{c}{ Variable } & No. $(\%)^{*}$ \\
\hline No. of all reoperations & $81(16.2)$ \\
\hline Reason for reoperation† & $72(88.9)$ \\
\hline Progression of spinal degeneration & $6(7.4)$ \\
\hline Wound infection & $3(3.7)$ \\
\hline Hematoma & $1(1.2)$ \\
\hline Wound dehiscence & \\
\hline Surgical procedure & $60(74.1)$ \\
\hline Laminectomy & $27(33.3)$ \\
\hline Discectomy & $33(40.7)$ \\
\hline Fusion & $21(25.9)$ \\
\hline Instrumented fusion & $12(14.8)$ \\
\hline In situ fusion &
\end{tabular}

* The percentage in the first row is based on the total number of cases in this study; percentages in the subsequent rows are based on the total number of reoperations.

† Nine patients had reoperations for causes other than spinal degeneration. One patient had two procedures. 


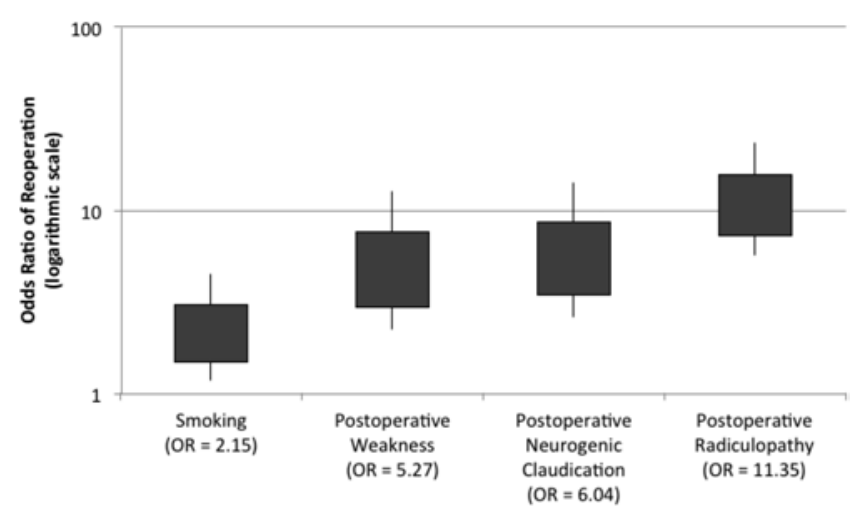

FIG. 2. Statistically significant predictors of all types of reoperation after laminectomies at 1, 2, or 3 levels. The graph shows the results of an analysis with multiple logistic regression testing for the effects of several comorbidities and conditions on the likelihood of reoperation. The boxes indicate ORs \pm standard error, and the error bars represent the $95 \% \mathrm{Cl}$.

trolling for sex, age, postoperative lower-extremity weakness, neurogenic claudication, and radiculopathy (Fig. 3). Of note, however, postoperative radiculopathy of the lower extremities was the strongest predictor of reoperation (OR $16.2, \mathrm{p}<0.001)$. For 9 patients undergoing reoperation for nondegenerative causes (hematoma, wound infection, or wound dehiscence), COPD (OR 16.2, $\mathrm{p}=0.01$ ) and coronary artery disease (OR 12.7, $\mathrm{p}=0.008)$ were both significant predictors of reoperation in the simple exact logistic regression. In an exact multiple logistic regression, only COPD predicted reoperation for these nondegenerative conditions (OR 8.92, $\mathrm{p}=0.03$ ).

Next, we stratified our data according to the number of lumbar spinal levels decompressed. In the single-level laminectomy group, an exact logistic regression was used to determine the statistically significant predictors of reoperation. We individually tested sex, age, comorbidities (coronary artery disease, diabetes mellitus, osteoporosis, obesity, smoking, COPD, hypertension, and depression), and postoperative symptoms (back pain, radiculopathy, weakness, sensory deficits, and neurogenic claudication) in the simple exact logistic regression. However, only smoking was a statistically significant predictor of reop-

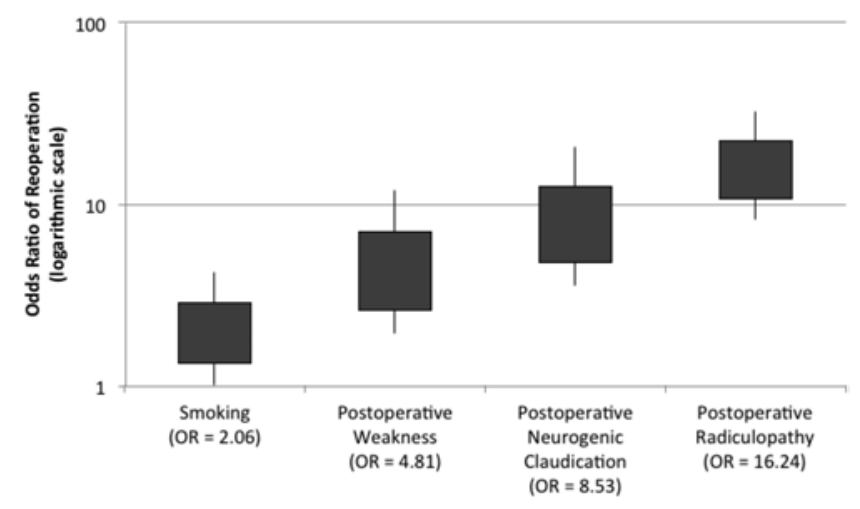

FIG. 3. Statistically significant predictors of reoperations for degenerative disorders after laminectomies at 1, 2, or 3 levels. The graph shows the results of an analysis with multiple logistic regression controlling for sex and age. The boxes indicate ORs \pm standard error, and the error bars represent the $95 \% \mathrm{Cl}$. eration (OR 11.2, $\mathrm{p}=0.02)$ in the single-level laminectomy cohort. After controlling for sex and age in the exact multiple logistic regression, smoking remained a statistically significant predictor of reoperation for patients in the single-level laminectomy group (OR $11.3, \mathrm{p}=0.02$ ) After we controlled for postoperative lower-extremity neurogenic claudication, weakness, and radiculopathy in the multilevel laminectomy group (that is, patients undergoing operations at 2 or 3 spinal levels), smoking remained a significant predictor of reoperation (OR 1.98, $\mathrm{p}=0.05)$. Of note, postoperative radiculopathy of the lower extremities was the strongest predictor of reoperation in the multilevel group (OR 10.7, p < 0.001) (Fig. 4).

Last, we examined the time to reoperation after a lumbar laminectomy. A Kaplan-Meier analysis of those patients followed up beyond the time of discharge indicated that the proportion of patients requiring reoperation was statistically significantly higher among smokers than among nonsmokers $(\mathrm{p}=0.04)$ (Fig. 5).

\section{Discussion}

The deleterious effects of smoking on lumbar fusions have been extensively documented in the literature. ${ }^{1,8,16} \mathrm{In}$ a rabbit model, Silcox et al. found that the detrimental agent in cigarettes was nicotine, which affected instrumented fusion. ${ }^{20}$ The effect of high nicotine levels on lumbar arthrodesis leads to instrumentation failure, pseudarthrosis, and adjacent-segment disease. ${ }^{3}$ However, the role of smoking on reoperation rates has not been well established in patients undergoing lumbar laminectomy without fusion. In a prospective study of 98 patients undergoing laminectomy for degenerative lumbar stenosis, Foulongne et al. found that high rates of preoperative comorbidity were associated with significantly higher rates of reoperation. ${ }^{5}$ However, no details of the comorbidities, as calculated by the Charleston score, were provided.

The purpose of the present study was to identify the statistically significant factors that predict reoperation in patients who had undergone a lumbar laminectomy for the first time. We found that, among various patient comorbidities, smoking was the only independent, statistically significant predictor of reoperation after both single-level and multilevel laminectomies (Figs. 2 and 4). Smoking

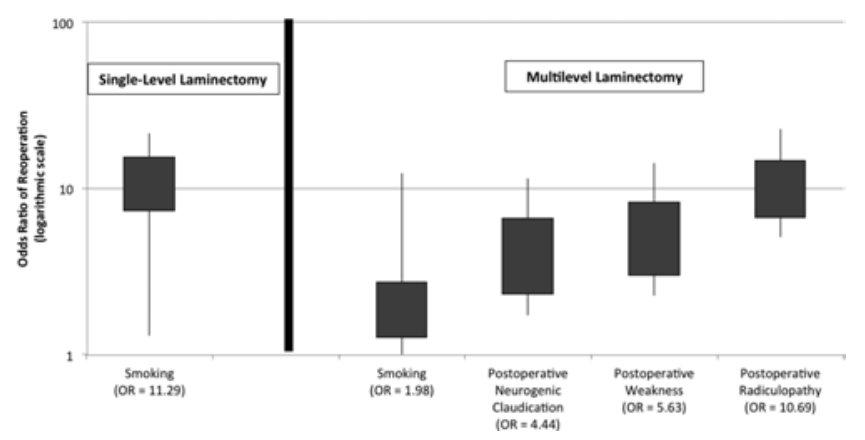

FIG. 4. Statistically significant predictors of all types of reoperation after single-level and multilevel laminectomies. The graph shows the results of an analysis with exact multiple logistic regression controlling for sex and age. The boxes indicate ORs \pm standard error, and the error bars represent the $95 \% \mathrm{Cl}$. 


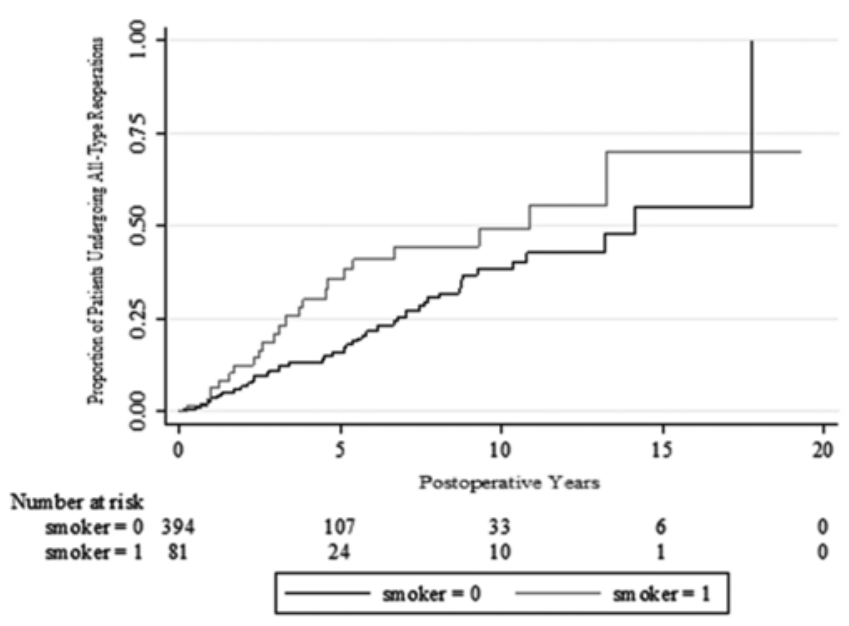

FIG. 5. Kaplan-Meier analysis indicating that the proportion of patients undergoing reoperation was statistically significantly higher in smokers (indicated as "smoker $=1$ ") than in nonsmokers ("smoker $=0$ ") $(p=$ 0.04).

also predicted an increased risk for reoperation due to progression of spinal degeneration (Fig. 3).

The causes for the higher reoperation rates among smokers are multifactorial. Smoking alters levels of those cytokines that increase bone metabolism and decrease bone mineral density. ${ }^{6}, 12$ In a study comparing smoking and nonsmoking between identical twins, Pocock et al. found that the risk for lumbar spine fractures increased 2-6-fold in those who smoke. ${ }^{18}$

Smoking has also been implicated as a potential risk factor for lower back pain, which may make it more likely that a surgeon suggests a reoperation. In a landmark publication in 1983, Frymoyer et al. reported that back pain was positively correlated with both the number of cigarettes per day and the number of smoking years. ${ }^{7}$ More recent studies have validated these findings. According to the Swedish Spine Register in 2011, smokers experience a statistically significantly higher prevalence of postoperative back pain at the 2-year follow-up, regardless of whether the patients underwent decompression alone or decompression plus fusion. ${ }^{19}$ The study suggests that smoking constricts the blood vessels near the vertebral body endplate, which decreases both nutrient entry into the intervertebral disc space and clearance of harmful toxins. Impairment of these processes leads to increased disc degeneration and early spondylosis, resulting in back pain.

Smoking has also been shown to be associated with degenerative disc disease. Battié et al. compared the MRI scans of the spine in identical twins differing in cigarette smoking. The imaging revealed an $18 \%$ greater disc degeneration in the lumbar spine among smokers than among nonsmokers. ${ }^{2}$ Similarly, examining disc degeneration in smokers, Nemoto et al. found that smoking causes partially irreversible damage to the anulus fibrosus.$^{15}$ Notably, the amount of mucin (proteoglycans) in the anulus fibrosus and nucleus pulposus increased after smoking was stopped.

In the present study, among patients with conditions not due to spinal degeneration (that is, hematoma, wound infection, or wound dehiscence) requiring a reoperation, COPD was the only statistically significant predictor of reoperation in the exact logistic analysis. The association of COPD with increased likelihood of reoperation may be explained by 2 different scenarios. Many individuals who have COPD also have a history of smoking, ${ }^{9}$ which has been shown to decrease the revascularization of the surgical site ${ }^{10}$ and to increase the risk for formation of an infectious nidus and for poor wound healing. In this scenario, COPD is the mediator in the connection between smoking and reoperation. Alternatively, those who have COPD typically show signs of hypoxia. ${ }^{17}$ Studies have repeatedly shown that tissue hypoxia strongly predicts poor wound healing. ${ }^{10}$ Therefore, COPD may increase the risk for reoperation independently of smoking.

Although these clinical and pathological effects of smoking and COPD on bone healing are permanent, smoking cessation may decrease the rate of decline in lumbar spine integrity. In a randomized controlled trial of patients undergoing surgery, Møller et al. found that a subcohort assigned to smoking cessation had a decreased risk for postoperative wound-related complications, cardiovascular complications, and secondary surgery. ${ }^{14}$ Thus, although surgical outcomes in past or present smokers may be worse than in those who never smoked, the benefits of smoking cessation should still be underscored during surgical consent discussions. To that end, although smoking was an independent risk factor for reoperation, postoperative lower-extremity weakness, neurogenic claudication, and radiculopathy also statistically significantly increased the odds of reoperation (Figs. 2-4). In fact, postoperative radiculopathy of the lower extremities was consistently the strongest predictor of all-type reoperations in the group undergoing laminectomy at a single level, reoperations for spinal degeneration in the same group, and all-type reoperations in the multilevel laminectomy group. Radiculopathy is a common clinical manifestation of nerve root compression due to spinal stenosis, degenerative disc disease, or focal lesions (including hematoma, abscess, and fluid collection). Thus, radiculopathy may be an important indicator of postoperative disorders at the index or the adjacent spinal level.

\section{Limitations}

Although the association between smoking and reoperation following a lumbar laminectomy were statistically and clinically significant, retrospective studies have inherent limitations. Our study was limited to information obtained from medical records. Therefore, the data were susceptible to reporting bias, most importantly the reporting of a patient's smoking history by the patient during clinic visits and by the health professional during updating of medical records. Consistent with other cohort studies, we assumed that patients lost to follow-up were exchangeable with those patients who either experienced the outcome measure (reoperation) or were administratively censored at the end of the follow-up period. Furthermore, the variables associated with spinal reoperation are complex and multifactorial. As such, regression models that identify determinants of reoperations are susceptible to residual confounding by unmeasured or unidentified covariates, which may attenuate or strengthen our reported association between smoking and poor surgical outcomes. 
Last, because of the limited sample size in the singlelevel laminectomy group ( $\mathrm{n}=38$ patients), the association between smoking and reoperation was expressed as a function of an exact logistic regression. Larger sample sizes of patients undergoing single-level laminectomy are required to estimate the effect of limited decompression on the association between smoking and reoperation. Future prospective, controlled trials are required to definitively establish that smokers have an increased risk for reoperation.

\section{Conclusions}

Of 500 patients undergoing first-time, lumbar laminectomy at 1,2 , or 3 levels for degenerative disease, 81 $(16.2 \%)$ underwent a reoperation. Among the comorbidities associated with these reoperations, smoking was the only independent, statistically significant predictor for reoperations including single-level and multilevel laminectomies. Smoking was also a statistically significant predictor of reoperation for progression of spinal degeneration. These findings suggest that smokers have worse outcomes after a lumbar laminectomy.

\section{References}

1. Andersen T, Christensen FB, Laursen M, Høy K, Hansen ES, Bünger C: Smoking as a predictor of negative outcome in lumbar spinal fusion. Spine (Phila Pa 1976) 26:2623-2628, 2001

2. Battié MC, Videman T, Gill K, Moneta GB, Nyman R, Kaprio J, et al: 1991 Volvo Award in Clinical Sciences. Smoking and lumbar intervertebral disc degeneration: an MRI study of identical twins. Spine (Phila Pa 1976) 16:1015-1021, 1991

3. Brown CW, Orme TJ, Richardson HD: The rate of pseudarthrosis (surgical nonunion) in patients who are smokers and patients who are nonsmokers: a comparison study. Spine (Phila Pa 1976) 11:942-943, 1986

4. Cobo Soriano J, Sendino Revuelta M, Fabregate Fuente M, Cimarra Díaz I, Martínez Ureña P, Deglané Meneses R: Predictors of outcome after decompressive lumbar surgery and instrumented posterolateral fusion. Eur Spine J 19:18411848,2010

5. Foulongne E, Derrey S, Ould Slimane M, Levèque S, Tobenas AC, Dujardin F, et al: Lumbar spinal stenosis: which predictive factors of favorable functional results after decompressive laminectomy? Neurochirurgie 59:23-29, 2013

6. Friedman AJ, Ravnikar VA, Barbieri RL: Serum steroid hormone profiles in postmenopausal smokers and nonsmokers. Fertil Steril 47:398-401, 1987

7. Frymoyer JW, Pope MH, Clements JH, Wilder DG, MacPherson B, Ashikaga T: Risk factors in low-back pain. An epidemiological survey. J Bone Joint Surg Am 65:213-218, 1983

8. Glassman SD, Anagnost SC, Parker A, Burke D, Johnson JR, Dimar JR: The effect of cigarette smoking and smoking cessation on spinal fusion. Spine (Phila Pa 1976) 25:26082615,2000
9. Godtfredsen NS, Lam TH, Hansel TT, Leon ME, Gray N, Dresler C, et al: COPD-related morbidity and mortality after smoking cessation: status of the evidence. Eur Respir J 32:844-853, 2008

10. Hopf HW, Hunt TK, West JM, Blomquist P, Goodson WH III, Jensen JA, et al: Wound tissue oxygen tension predicts the risk of wound infection in surgical patients. Arch Surg 132:997-1005, 1997

11. Katz JN, Lipson SJ, Brick GW, Grobler LJ, Weinstein JN, Fossel AH, et al: Clinical correlates of patient satisfaction after laminectomy for degenerative lumbar spinal stenosis. Spine (Phila Pa 1976) 20:1155-1160, 1995

12. Leino A, Impivaara O, Järvisalo J, Helenius H: Factors related to risk of osteoporosis in 50-year-old women. Calcif Tissue Int 49 (Suppl):S76-S77, 1991

13. Malter AD, McNeney B, Loeser JD, Deyo RA: 5-year reoperation rates after different types of lumbar spine surgery. Spine (Phila Pa 1976) 23:814-820, 1998

14. Møller AM, Villebro N, Pedersen T, Tønnesen H: Effect of preoperative smoking intervention on postoperative complications: a randomised clinical trial. Lancet 359:114-117, 2002

15. Nemoto Y, Matsuzaki H, Tokuhasi Y, Okawa A, Uematu Y, Nishimura T, et al: Histological changes in intervertebral discs after smoking and cessation: experimental study using a rat passive smoking model. J Orthop Sci 11:191-197, 2006

16. Patel TC, Erulkar JS, Grauer JN, Troiano NW, Panjabi MM, Friedlaender GE: Osteogenic protein-1 overcomes the inhibitory effect of nicotine on posterolateral lumbar fusion. Spine (Phila Pa 1976) 26:1656-1661, 2001

17. Pierson DJ: Pathophysiology and clinical effects of chronic hypoxia. Respir Care 45:39-53, 2000

18. Pocock NA, Eisman JA, Kelly PJ, Sambrook PN, Yeates MG: Effects of tobacco use on axial and appendicular bone mineral density. Bone 10:329-331, 1989

19. Sandén B, Försth P, Michaëlsson K: Smokers show less improvement than nonsmokers two years after surgery for lumbar spinal stenosis: a study of 4555 patients from the Swedish Spine Register. Spine (Phila Pa 1976) 36:1059-1064, 2011

20. Silcox DH III, Daftari T, Boden SD, Schimandle JH, Hutton WC, Whitesides TE Jr: The effect of nicotine on spinal fusion. Spine (Phila Pa 1976) 20:1549-1553, 1995

\section{Author Contributions}

Conception and design: M. Bydon, Macki, Sciubba, Gokaslan. Acquisition of data: Macki. Analysis and interpretation of data: M. Bydon, Macki, De la Garza-Ramos, Gokaslan. Drafting the article: M. Bydon, Macki, De la Garza-Ramos. Critically revising the article: M. Bydon, Macki. Reviewed submitted version of manuscript: all authors. Approved the final version of the manuscript on behalf of all authors: A. Bydon. Statistical analysis: Macki. Administrative/technical/material support: A. Bydon, Sciubba, Wolinsky, Gokaslan, Witham. Study supervision: A. Bydon, Sciubba, Wolinsky, Gokaslan, Witham.

\section{Correspondence}

Ali Bydon, Johns Hopkins Hospital, Department of Neurosurgery, Meyer Building 7-109, 600 N. Wolfe St., Baltimore, MD 21287. email: abydon1@jhmi.edu. 